\title{
La peregrinación a Jerusalem a finales del siglo $\mathrm{XV}$
}

\author{
Pedro TEnA TEnA \\ Instituto Cervantes
}

\section{Primeros pasos}

Las suaves lluvias de abril han penetrado hasta lo más profundo de la sequía de marzo y empapado todos los vasos con la humedad suficiente para engendrar la flor; el delicado aliento de Céfiro ha avivado en los bosques y campos los tiernos retoños y el joven sol ha recorrido la mitad de su camino en el signo de Aries; las avecillas, que duermen toda la noche con los ojos abiertos, han comenzado a trinar, pues la Naturaleza les despierta los instintos. En esta época la gente siente el ansia de peregrinar, y los piadosos viajeros desean visitar tierras y distantes santuarios en extraños países [...] ${ }^{1}$.

El viaje ha existido siempre en el acontecer humano ${ }^{2}$, señalábamos en cierta ocasión ${ }^{3}$. Y los numerosos testimonios literarios reflejando la experiencia del desplazamiento que se han escrito a lo largo de los siglos no han dejado de satisfacer curiosidades e

${ }^{1}$ Geoffrey Chaucer, Cuentos de Canterbury, ed. Pedro Guardia Massó (2a ed. Madrid 1991) pág. 65.

${ }^{2}$ Lionel CAsson, Travel in the Ancient World (Baltimore-London 1994), y para ejemplos literarios Relatos de viajes en la literatura griega antigua, ed. Luis A. GARCía Moreno y F. Javier Gómez EsPelosín (Madrid 1996). Como introducción para la época medieval véase Travel and Travellers of the Middle Ages, ed. Arthur PERCIVAL NewTON (London 1949) y para ejemplos literarios Jean RICHARD, «Les récits de voyages et de pèlerinages», en Typologie des sources du Moyen Âge Occidental, dir. Léopold GeNICOT (Turnhout 1981).

${ }^{3}$ En mi artículo «Roma en textos españoles de viajes medievales», Lemir 3 (1998-1999) (http://parnaseo.uv.es/Revista/Revista3/Tena/Articulo.htm); allí dedicábamos también unas líneas a las motivaciones generales para emprender un viaje, en particular el de tipo religioso. 
inquietudes. No obstante, la amplia y reciente investigación ha procurado ofrecer nueva perspectiva de esta clase de textos bajo un tratamiento comparativo e interdisciplinar. $Y$ así hoy se consideran esos textos como esenciales en el estudio de la génesis de la novela ${ }^{4} \mathrm{y}$ en otros casos se les da mayor valor como útil herramienta para el acercamiento histórico y geográfico por los variados cuadros descriptivos que contienen (arterias de economía, ciudades, distancias, gobiernos, riquezas, tipos de población con sus costumbres, creencias, lengua, etc.) ${ }^{5}$. $\mathrm{Y}$ es en este segundo contexto donde hemos de situar la razón del presente artículo: conocer un poco más cómo eran los desplazamientos de los cristianos palmeros en los términos del Medievo basándonos en uno de los últimos escritos de peregrinación conocidos en España en ese tiempo, la traducción española del Viaje de la Tierra Santa del alemán Bernardo de Breidenbach, impresa en Zaragoza por Paulo Hurus en $1498{ }^{6}$.

\section{EL VIAJE}

Con latín, rocín y florín, andarás el mundo hasta el fin, y podrás ver el Miramamolín ?

\subsection{El camino}

8 de enero de 1484. Aquel día en Venecia, bajo una atmósfera repleta con sones de campanas, el deán Bernardo de Breidenbach

${ }^{4}$ Percy G. ADAMS, Travel Literature and the Evolution of the Novel (Lexington 1983), y Sofía M. CARRIzo RUEDA, «Un elemento generador de la novela moderna: los libros de viajes de la España medieval», en La cultura hispánica y Occidente: Actas del IV Congreso Argentino de Hispanistas (Mar del Plata 1997) págs. 206-210.

5 José A. OCHOA, «El valor de los viajeros medievales como fuente histórica», Revista de Literatura Medieval 2 (1990) págs. 85-102.

${ }^{6}$ Bernardo de BREIDENBACH, Viaje de la Tierra Santa (Zaragoza 1498); Hugh Wm. DAviES, Bernhard von Breydenbach and his Journey to the Holy Land, 1483-4: A Bibliography (London 1911); Heinrich ROHRBACHER, «Bernhard von Breydenbach und sein Werk Peregrinatio in Terram Sanctam (1486)", Philobiblon 33 (1989) págs. 89-113; y Pedro TENA TENA, La labor literaria de Martín Martínez de Ampiés y el Viaje de la Tierra Santa (Madrid 1995).

${ }^{7}$ Gonzalo CoRreas, Vocabulario de refranes y frases proverbiales y otras fórmulas comunes de la lengua castellana en que van todos los impresos antes y otra gran copia, ed. Víctor INFANTES (Madrid 1992) pág. 125. 
regresaba de los Santos Lugares ${ }^{8}$; dejaba atrás todo un pasado de gozo, pero también de algún que otro pesar, como la muerte de su compañero de viaje el conde de Solms. Cierto es que la visita a los escenarios de vida de Jesucristo sobreestimularían a cualquier peregrino antes de iniciar su travesía; sin embargo, ello no quitaba una terrena organización.

En un tiempo marcado por no pocas inseguridades en lo referente a las romerías hacia Jerusalem, la simple idea de llevar a cabo aquella experiencia exigía tomar las adecuadas medidas ${ }^{9}$. Verdad es que a finales del siglo XV ya se conocía la existencia de «compañías de viajes» encargadas de organizar tales trayectos desde la urbe véneta ${ }^{10}$ y que a la experiencia que aquellas brindaran se añadía la de otros viajeros que ya habían ido a Tierra Santa y que podían acompañar al peregrino inexperto ${ }^{11}$; sin embargo, muchos viajeros se ocuparían de adquirir previamente una buena preparación (y documentación) no sólo para enfrentarse a una «realidad» nueva, sino también para colmar una cierta curiosidad intelectual ${ }^{12}$. Y es que no faltaban instrumentos literarios para satisfacer toda inquietud, incluso sin contar las ilustraciones geográficas tan del gusto de

\footnotetext{
${ }^{8}$ BREIDENBACH fol. $161 \mathrm{v}_{2}$. Los recibimientos sonoros al viajero foráneo formaban parte, incluso en el Extremo Oriente, del ritual del «camino», y así lo leemos, por ejemplo, en Ibn BATTUTA, $A$ través del Islam, ed. Serafín Fanjul y Federico ARBós ( $1^{\text {a }}$ reimpr. Madrid 1989) pág. 727 , aunque en este caso sea un testimonio del siglo XIV.

${ }^{9}$ En época antigua la marcha a Palestina parecía estar reservada a espíritus arrojados. Véase E. D. HUNT, Holy Land Pilgrimage in the Later Roman Empire A. D. 312-460 (Oxford 1982); Pierre Maraval, Lieux Saints et pelerinages d'Orient (Paris 1985); y también, como ejemplo, EGERIA, Itinerario de la virgen Egeria (381-384), ed. Agustín ARCE (Madrid 1996). No obstante, en el siglo VIII, so el amparo carolingio, cambiaron algo las circunstancias de los viajes palmeros; véase Steven Runciman, Historia de las Cruzadas (3ª reimpr. Madrid 1987) vol. I págs. 54-55. Sobre el rey franco y las peregrinaciones a Jerusalem véase Le pèlerinage de Charlemagne, La peregrinación de Carlomagno, ed. Isabel de RIQUER (Barcelona 1984). Y lo mismo ocurrió en el siglo X con la Orden de Cluny; véase RUNCIMAN Cruzadas vol. I págs. 57 y 59.

${ }^{10}$ BREIDENBACH fols. $41 \mathrm{r}_{2}$ y $142 \mathrm{r}_{2}$, y Friedrich UHLHORN, «Zur Geschichte der Breidenbachschen Pilgerfahrt», Gutenberg-Jahrbuch (1934) pág. 110, por ejemplo.

${ }^{11}$ Es el caso de Félix Fabri en el viaje con que iniciamos nuestro artículo (BREIDENBACH fol. 142 $\mathrm{v}_{1}$; DAVIES Breydenbach págs. IV-VI).

${ }^{12}$ En relación con esto último, semejante actitud en personas como el citado canónigo Bernardo de Breidenbach vendría dada por una estimable formación universitaria, palpable ya desde el siglo XIII en la mayoría de los religiosos que visitaban los Santos Lugares; véase F. E. PeTERs, Jerusalem (Princeton 1985) pág. 515.
} 
finales del XV ${ }^{13}$. La misma Biblia ${ }^{14}$, guías de Tierra Santa, ya espirituales ${ }^{15}$ ya procesionales ${ }^{16}$, libros de viajes que relataban experiencias de peregrinación a Palestina y también obras de talante semejante ${ }^{17}$, como textos de indulgencias ${ }^{18}$, eran muy buenas ayudas ${ }^{19}$, según lo demostraría Fadrique Enríquez de Ribera para su viaje de $1518^{20}$.

${ }^{13}$ Sobre mapas y vistas de Tierra Santa a lo largo de la Edad Media, véase, por ejemplo, Kenneth NeBENZAHL, Maps of the Bible Lands: Images of Terra Sancta Through Two Millennia (London 1986), y Journeys to the Promised Land (New York 1989). Este interés por la imagen del «espacio» estuvo también a veces teñido por una afición por lo exótico (Claude KAPPLER, Monstruos, demonios y maravillas a fines de la Edad Media [Madrid 1986]) y en otras ocasiones por un gusto humanista hacia lo geográfico (Ángel GómEZ Moreno, España y la Italia de los humanistas: Primeros pasos [Madrid 1994] pág. 320). $\left.75 r_{1}\right)$

${ }^{14}$ En nuestro propio texto se hace indirecta mención de ello (BREIDENBACH fol.

${ }^{15}$ Como el «directorio» de san Bernardo que forma parte de su De la loa a la nueva milicia, a los soldados del Temple (BERNARDO, Obras de San Bernardo, ed. Germán PRADO [Madrid 1947] págs. 1447-1463).

${ }^{16}$ Véase, por ejemplo, Manuel de CASTRO, «Dos itinerarios de Tierra Santa de los siglos XIV y XV», Hispania Sacra 10 (1957) págs. 443-486, y J. G. DAVIES, «A fourteenth century Processional for Pilgrims in the Holy Land", Hispania Sacra 41 (1989) págs. 421-429.

${ }_{17}$ Titus TOBLER, Bibliographia Geographica Palaestinae (Leipzig 1867); Girolamo Golubovich, Biblioteca bio-bibliografica della Terra Santa e dell'Oriente francescano (Quaracchi 1906-1927); Reinhold RÖHRICHT, Bibliotheca Geographica Palaestinae (Jerusalem 1963); y Nathan SCHUR, Jerusalem in Pilgrims and Travellers 'Accounts (Jerusalem 1983).

${ }^{18}$ DAVIES Breydenbach pág. 429.

19 Una muestra de la cantidad de los variados datos que podían contener estos escritos es el tratamiento que se hacía de las lenguas, como puede comprobarse en nuestro Viaje de la Tierra Santa. El hecho de señalar las lenguas de los variados grupos sociales residentes en Jerusalem, recogiendo la representación gráfica de los respectivos alfabetos y también una lista de 228 palabras árabes con su traducción al latín, vocabulario que se omite en la versión española (DAviEs Breydenbach pág. X), supone el claro propósito de dotar al texto de valor práctico. Vemos lo mismo en otras obras hispanas de viaje: el Liber peregrinationis, donde hallamos una relación de vocablos vascuences (Guía del peregrino medieval "Codex Calixtinus"), ed. Millán Bravo LOZANO [3 $3^{\mathrm{a}}$ ed. Sahagún 1989] págs. 36-37 y 115-116; y la obra de J. de Mandevilla traducida al aragonés (J. de MANDEVILLA, Libro de las maravillas del mundo [Zaragoza 1979] págs. 51, 69, 82, 85-86 y 86). Véase también RicHARD «Les récits» pág. 67.

Las obras de peregrinación resultaban también muy interesantes en el campo bélico, pues a la hora de organizar una empresa de conquista «cruzada» era muy conveniente conocer el entorno del objetivo (RICHARD «Les récits» págs. 18 y 69 72). Para el tiempo que nos ocupa, el del reinado de los Reyes Católicos, acúdase a José GARCÍA ORO, De Granada a Jerusalén ... La cruzada del cardenal Cisneros (Madrid 1991) págs. 724-763.

${ }^{20}$ Pedro García Martín, La Cruzada Pacífica (Barcelona 1997) págs. 20-21 y 61. 
Cuando un europeo en el Occidente del Cuatrocientos decidía realizar un viaje a Palestina con el objeto de visitar aquellos lugares de tanta significación para un cristiano, podía escoger entre varias clases de rutas, que variaron a lo largo de los siglos.

El período del auge peregrino comenzó en el siglo $\mathrm{X}{ }^{21}$. $\mathrm{Y}$ a partir de entonces se desarrolló en gran medida la vía por tierra, sobre todo después de 975 tras la conversión a la fe cristiana de los monarcas húngaros, quienes hicieron más factible un camino que, siguiendo el curso del Danubio, atravesaba zonas balcánicas hasta Constantinopla. Aun con todo, este trayecto no estuvo exento de peligros que empezaron a disminuir hacia 1019, cuando Bizancio logró domeñar aquellas tierras. Así, en este primer tramo el palmero podía incluso elegir entre dos posibles rutas: una, por Hungría para luego pasar por Belgrado, Sofía y Adrianópolis hasta la capital de Constantino; y otra, encaminarse a la Italia bizantina y viajar de Bari a Dirraquio para luego tomar la romana vía Ignacia por Tesalónica y topar con el Bósforo. Por medio de tres calzadas llegaba luego el peregrino por el Asia Menor a Antioquía; y siguiendo la costa, alcanzaba la meta santa de Jerusalem ${ }^{22}$. La pérdida de San Juan de Acre en 1291 y la toma de Constantinopla en 1453 supondrán serios contratiempos para las facilidades del trayecto.

En los momentos en que viaja Bernardo de Breidenbach la situación era la siguiente:

$@$ La dicha ciudad [Parens] es puesta en tierra mucho hermosa y delectable: y dende pueden passar por tierra fasta vngria $/ y$ en otros reynos: y ahun podrian dende passar por tierra firme fasta el sepulcro del redemptor en jherusalem: empero seria muy peligroso 'que no se pudiera cobrar de ligero el saluo conducto: sin el qual nadie en tantas tierras de infieles passar no puede ' ni tal consejo es de dar jamas 'y delo tentar es mucha locura ${ }^{23}$.

Por su parte los viajes por mar contaron a lo largo de los tiempos con una relativa facilidad. En un principio dos factores contribuyeron a que el tráfico marítimo gozara de una cierta seguridad: 1) la sucesiva pérdida del dominio del Mediterráneo por parte de

${ }^{21}$ Runciman Cruzadas vol. I pág. 55.

${ }^{22}$ Runciman Cruzadas vol. I pág. 59.

${ }^{23}$ BREIDENBACH fol. $46 \mathrm{v}_{2}$. 
los árabes, motivada en la décima centuria por la caída de los núcleos de piratería -establecidos principalmente en la península de los Apeninos y en la costa meridional francesa-y por la liberación de Creta en 961; y 2) la hegemonía que los bizantinos establecieron en el Mediterráneo. Si a esto se unía el comercio entre griegos e italianos y el vínculo comercial entre cristianos y musulmanes, al eliminarse trabas en las relaciones con Egipto y con Siria, el peregrino podía alcanzar directamente desde Venecia las costas de Alejandría, Bari, Trípoli, etc. A pesar de ello no era extraño que los viajeros eligiesen pasar a Tierra Santa desde Constantinopla, antes de su caída, con el fin de contemplar las innumerables reliquias que en sus templos se guardaban.

En los últimos años medievales Venecia era una potencia marítima cuyas colonias establecidas por todo el Mediterráneo la convertían en un centro neurálgico comercial al tiempo que constituían valiosos apoyos para el crecimiento de su política económica:

O quanto serias marauillado letor quandoquiera que arribasses en estas partes de su señoria 'que su potestad alcança la Hystria fasta Dalmacia y la Sclauonia: y dende sale fasta la grecia. Tiene a Cipre tiene a Candia yslas reales: y es señora de muchas gloriosas ciudades del mar'y poderosas jnsulas grandes 'y senos y puertos: los quales nombrar aqui seria mucho prolixo $[\ldots]^{24}$.

En alexandria embian seys naues. dos en damasco. dos en baruto. dos en las regiones que son estranyeras siquier barbaras 'fuera del trato y entender comun de nosotros. otras dos embian en constantinoble. dos en joppen siquiere japha: en las quales passan los peregrinos ala tierra santa. otras dos passan en anglaterra. y otras tantas al puerto de flanders fuser llamado $[\ldots]^{25}$.

\footnotetext{
24 BREIDENBACH fol. $43 \mathrm{v}_{2}$.

${ }^{25}$ BREIDENBACH fol. $45 r_{1}$. Esta visión del comercio véneto se nos muestra refrendada por los comentarios de Pedro Mártir de Anglería durante su estancia en aquel lugar: «Diuersarum enim mercium comparandarum gratia ad omnes has regiones veneti quotannis quendam galleacearum numerum destinant. Ad tanaym scilicet scithiam aliquas, alias berutum damasci portum in syriam, alexandriam aegypti emporium alias, ad africana littora plerasque, quasdam in hispaniam, in angliam Britaniam maiorem et ad glacialis occeani accolas etiam nonnullas mittunt, byzantium quoque constantinopolim in thraciam (priusquam turcharum bellis urgeretur) unde tapetum ingentem copiam referebant mittere consueuerant» (Pedro Mártir de Anglería, Una embajada de los Reyes Católicos a Egipto, ed. Luis García García [Valladolid 1947] pág. 43).
} 
Uimos el nombrado puerto de Thor eneste mar mismo: donde arriban todos los nauios que dela jndia vienen cargados de specieria: y dende passan en Alexandria y fasta venecia porque se derramen alas otras partes que no las alcançan ${ }^{26}$.

No es extraño, pues, que muchos eligiesen dicho lugar como el inicio de su peregrinación, consideración que a las autoridades vénetas les interesaba sin duda fomentar por el complejo negocio que se movía en torno a los palmeros:

COmo la antigua y clara ciudad de los Uenecianos sea vn termino del qual 'y por donde se toma principio para el santo peregrinaje 'alos que quieren el mar nauegar [... $]^{27}$.

El peregrino podía escoger varios caminos por mar desde la localidad italiana hasta Tierra Santa, siguiendo siempre una ruta marcada por las posesiones señoriales o la presencia de los venecianos en las zonas costeras ${ }^{28}$.

En testimonios literarios y tan solo fijándonos en la Palestina marítima como destino, encontramos, por ejemplo, trayectos que unían directamente Venecia con Beirut: dan muestra de ello rabí Yosef da Montagna (1481), rabí Obadyah da Bertinoro (1488) y un discípulo de este (1495) ${ }^{29}$. Según la vivencia de nuestro deán, lo más corriente era que desde la ciudad véneta se llegase a Jaffa ${ }^{30}$. Esta ruta tenía una variante: no volver a embarcarse en el

${ }^{26}$ BREIDENBACH fol. $145 \mathrm{v}_{2}$.

${ }^{27}$ BREIDENBACH fol. 43r $r_{2}$. Uno de los comercios fue el de textos útiles para la marcha a Tierra Santa: guías, obras que anotaban indulgencias, etc. Véase Béatrice DANSETTE, «Les pèlerinages occidentaux en Terre Sainte: une pratique de la "Devotion Moderne" à la fin du Moyen Âge? Relation inèdite d'un pèlerinage effectué en 1486", Archivum Franciscanum Historicum 72 (1979) pág. 123; y RICHARD «Les récits» pág. 18.

${ }^{28}$ En cuanto al tiempo de partida desde la ciudad italiana, el español Pero Tafur nos habla del mes de mayo (Pero TAFUR, Andanças e viajes de un hidalgo español: Pero Tafur (1436-1439), ed. Marcos JimÉnez DE LA EsPADA [y José VIVES GATELL] [Barcelona 1982] pág. 41), y nuestro Bernardo de Breidenbach, del 1 de junio (BREIDENBACH fol. $46 \mathrm{v}_{1}$ ).

${ }^{29}$ Relatos de viajes y epístolas de peregrinos judios a Jerusalén (1481-1523), ed. José Ramón MAGdalenA NOM DE DÉU (Sabadell 1987) págs. 19, 21, 29, 95, 105 y 151-154. Véase también Haïm HaRboUn, Les Voyageurs juifs $d u X I I I^{c}, X^{\prime} V^{c}$ et $X V^{e}$ siècles (Aix-en-Provence 1988).

${ }^{30}$ Para un primer acercamiento al contexto económico, geográfico, histórico y humano que envuelve esta vía hay que tener presente las aportaciones de José A. OCHOA ANADÓN, «El viaje de Tafur por las costas griegas, I», Erytheia 8 (1987) págs. 33-62. 
mismo sitio ${ }^{31}$, sino continuar hasta el monte del Sinaí ${ }^{32}$ y luego a Alejandría para tomar el barco de regreso ${ }^{33}$. Como veremos a continuación ese itinerario se podía también hacer a la inversa: Venecia, Alejandría, monte del Sinaí y Jerusalem.

De todo lo anterior podría entenderse que Venecia tenía el monopolio de los viajes por mar de los peregrinos; sin embargo y aparte de su importantísimo papel en relación con Tierra Santa, la idea no es totalmente cierta ${ }^{34}$, pues podemos encontrar ejemplos de otros puntos de partida en el período que tratamos. Y así los viajeros judíos Mešul lam da Volterra (1481) y rabí Obadyah da Bertinoro (1488) son sólo un par de ejemplos: el primero navega bajo las órdenes de un patrón genovés y el segundo toma una nave francesa; ambos, para ir primero a Alejandría ${ }^{35}$ y de allí a Jerusalem.

El camino de hombres y mujeres españoles en sus viajes a los Santos Lugares en las postrimerías de la Baja Edad Media y principios del siglo XVI no variaba mucho del de otros palmeros europeos occidentales de la época. Y así vemos desplazamientos de Venecia a Jaffa a través de las diferentes posesiones de la ciudad republicana. Es el caso, por ejemplo, de Antonio de Lisboa $(1507)^{36}$ o de Diego de Mérida (1507-1512) ${ }^{37}$.

${ }^{31}$ BREIDENBACH fols. $74 r_{2}$ y $142 r_{2}$.

${ }^{32}$ Félix Fabri, por ejemplo, nos indica que la caravana a la que se unió para hacer este trayecto la formaban 30 asnos, 25 camellos, 6 burreros, 7 camelleros, 2 guías árabes, 2 intérpretes con 1 esclavo y 18 palmeros. Al grupo inicial se fueron uniendo otras personas hasta alcanzar el número de 60; véase Félix FABRI, Voyage en Egypte de Felix Fabri, 1483, ed. Jacques Masson [y Giséle Hurseaux] (Caire 1975) vol. I pág. III.

${ }^{33}$ Por sus peligros no eran muchos los que se aventuraban por esta ruta; véase Jean-Marc PASTRÉ, «De Gaza au Sinaï: Les récits de pèlerins allemands au XVe siècle», en Les récits de voyage (Paris 1986) págs. 13-24.

${ }^{34}$ Véase David JACOBY, «Pèlerinage médiéval et sanctuaires de Terre Sainte: La perspective vénitienne», Ateneo Veneto 24 (1986) págs. 27-58, quien no sólo se ocupa de los últimos años del Medievo.

${ }^{35}$ Magdalena NOM De DéU Relatos págs. 11-13 y 41-48, 21-22 y 106-112, respectivamente. Véase HARBOUN Les Voyageurs.

${ }^{36}$ Fray Antonio de Lisboa, Viaje a Oriente (1507), ed. Antonio Rodríguez MoÑino (Badajoz, 1949) págs. 13-67 (es posible que se trate de un portugués que escribe su obra en español).

${ }^{37}$ Antonio Rodríguez MoÑino, «Viaje a Oriente de Fray Diego de Mérida», Analecta Sacra Tarraconensia 18 (1945) págs. 120-126. 
Una segunda posibilidad era llegar a Alejandría desde la localidad véneta para luego pasar a Jerusalem; esta pudo ser la ruta seguida por Antonio Cruzado (1484-1487) ${ }^{38}$. Esta vía no nos parece rara en el hispano, teniendo en cuenta no sólo su presencia en Italia y el potencial marítimo de Venecia, sino también y aparte de los ejemplos ya mencionados, la peregrinación que se describe someramente en el Tirant lo Blanch (1490) ${ }^{39} \mathrm{y}$ el hecho de que Pedro Mártir de Anglería (1501-1502), siguiendo desde Granada un itinerario terrestre, tomara luego una nave en Venecia rumbo a Alejandría ${ }^{40}$.

De todo lo dicho se deduce que no siempre se viajó a Palestina desde el norte de la península de los Apeninos: las conexiones de la Corona de Aragón con los soldanes de Egipto hicieron factibles las peregrinaciones marítimas directas desde las costas ibéricas y no sólo en las postrimerías del siglo XV ${ }^{41}$. Por los estudios consultados parece que Barcelona fue un puerto fundamental en semejantes contactos. Y así encontramos la siguiente noticia procedente de los Llibres de Dietaris, que nos han traducido:

${ }^{38}$ Suponemos que embarcó en Venecia porque no hemos podido consultar el texto completo de la obra, que se conserva en la Bibliothèque Nationale de París según Agustín ARCE, «Dos custodios de Tierra Santa desconocidos, 1484-1490», Archivum Franciscanorum Historicum 57 (1964) pág. 424. El ejemplar que se guarda en la biblioteca particular de Bartolomé March Servera, cuya lectura nos ha facilitado María Dolores Vives Miquel, carece del (último) folio, donde se habla de la permanencia de nuestro personaje en Italia (Antonio Cruzado, Los misterios de Jerusalem [Sevilla 1529]).

39 Joanot MARTORELl y Marti Joan de Galba, Tirant lo Blanch (Valencia 1978) fols. $a 4 v_{1}-a 4 v_{2}$. Se ha de tener presente que la obra se concluyó en 1464 (Fernando LÁzaro Carreter, «La pluma y la espada», ABC Cultural 62 [8 enero 1993] pág. 7).

${ }^{40}$ MÁRTIR DE ANgLería Una embajada págs. 22-87. La ruta egipcia era asequible asimismo por otros puertos: en un segundo viaje Diego de Mérida alcanza Damieta desde la isla de Chipre con el objeto de llegar al monte del Sinaí (RoDRÍGUEZ MOÑino Viaje a Oriente págs. 145-187).

${ }^{41}$ En un ámbito más restingido véase, por ejemplo, Josep GUDiol, «De peregrins i peregrinatges religiosos catalans», Analecta Sacra Tarraconensia 3 (1927) págs. 93-103. Y en un marco general, MÁRTIR DE ANGLERía Una embajada; Luis SUÁREZ FERNÁNDEZ, «Las relaciones de los Reyes Católicos en Egipto», en En la España Medieval: Estudios dedicados al profesor D. Julio González González (Madrid 1980) págs. 507-519; y Charles-Emmanuel DuRFourCQ, «La continuité des activités catalano-aragonaises dans les états musulmans méditerranéens d'Alphonse le Magnanime à Ferdinand le Catholique», en $I X$ Congresso di Storia della Corona d'Aragona (Napoli 1982) vol. II págs. 199-223. 
Jueves 20 de Abril [de 1391] se hizo a la vela la Coca de Guillermo Rierola y de otros, que con peregrinos Castellanos pasaba a Jafa (puerto de Syria) ${ }^{42}$.

Tampoco en esos lazos catalanes se quedaba atrás la localidad de Alejandría. Teniendo en cuenta los múltiples nexos comerciales y políticos con el soberano mameluco, era comprensible que se dieran con asiduidad viajes de palmeros con destino a la urbe egipcia en su trayecto a Jerusalem ${ }^{43}$. Nuestro texto asimismo refleja este cuadro económico:

Al cabo traydos en el palacio del rey de Sicilia: donde sta el consul delos cathelanes: fue nos ende hecho buen recebimiento: dando nos estancias a cadavno. Esta es casa donde la dicha generacion tiene vna plaça para los negocios de mercaderias: en la qual suelen aposentar los peregrinos: ahun que tengan otras dos plaças 'o hondigas los venecianos 'y otra los genoeses: porque son muy bien aqui defendidos del consul dicho 'con mucho fauor del trucheman siquier Eraute alexandrino: por el qual fueron luego presentados ante el Admiraldo dela ciudad los caualleros y nobles nuestros. del qual recebidos con gran cortesia: mando en vn libro screuir sus nombres y los dexo boluer ala posada. Ende algunos compañeros nuestros hecha concordia con el dicho consul 'aquellos dias con el comieron: seruidos de plata mas que de viandas. los otros quedaron con el señor Conde en su aposiento ${ }^{44}$.

Aunque el conocimiento de semejantes datos daba una mayor confianza al romero de la época, aunque se contaba previamente con las bendiciones en los «ritos de partida» ${ }^{45}$ y aunque existía la fe en la protección divina para el palmero ${ }^{46}$, la realidad se encar-

\footnotetext{
${ }^{42}$ Antonio de CAPMANY Y DE MONPAlaU, Memorias históricas sobre la marina, comercio y artes de la antigua ciudad de Barcelona (Barcelona 1963) vol. II (2) pág. 842.

${ }^{43}$ José M. MADURELl y MARIMón, «Cuentas de un viaje comercial a Rodas y Alejandría en 1438», en Miscelánea de Textos Medievales 2 (1974) págs. 229-234 y Amada LÓPEZ DE MENESES, «Un siglo del consulado de los catalanes en Alejandría (1416-1516)», en IX Congresso di Storia della Corona d'Aragona págs. 225 242.

${ }^{44}$ BREIDENBACH fol. $155 \mathrm{r}_{2}$.

${ }^{45}$ Esta clase de ceremonias se nos describen, por ejemplo, en un ordinario gerundense de 1502 o en un ritual de Vich de 1509 (GUDIOL «De peregrins» págs. 112-113). Sobre sus precedentes véase José JANINI, «Influjos visigóticos en "misas de viajeros" del siglo VIII", Hispania Sacra 39 (1987) págs. 15-24.

${ }^{46}$ BREIDENBACH fol. $3 v_{2}$.
} 
gaba de matizar tales aspectos. Y es que el riesgo de desgracias era algo manifiesto en el Mediterráneo de 1483 y 1484, las cuales daban al traste en muchas ocasiones con el tranquilo desarrollo de la navegación ${ }^{47}$. No sólo hallamos los peligros provocados por el hombre, como el conflicto bélico entre el soberano de Venecia y los duques de «ferrara» y «lotringia» ${ }^{48}$, entre aquel y el rey de Napoles ${ }^{49}$, la presencia de corsarios y piratas 50 o el peligro turco ${ }^{51}$, sino también problemas de índole natural, ya externos -como fortunas ${ }^{52}$ y nieblas ${ }^{53}$-, ya internos - como enfermedades y padeceres propios de las embarcaciones de aquellos tiempos ${ }^{54}$.

${ }^{47}$ En un contexto amplio véase Jean RICHARD, «Les gens de mer vus par les Croisés et par les pèlerins occidentaux du Moyen-Âge», en su obra Croisés, missionnaires et yoyageurs (London 1983) pág. 345. Este estudio es muy interesante para conocer detalles de la intrahistoria marítima de nuestro viaje por la incorporación de curiosas noticias procedentes del texto de Félix Fabri que no se incluyen en el de Bernardo de Breidenbach.

${ }^{48}$ BREIDENBACH fols. $45 \mathrm{r}_{2}$ y $54 \mathrm{r}_{1}$.

${ }^{49}$ BREIDENBACH fol. $156 \mathrm{r}_{1}$.

${ }^{50}$ BREIDENBACH fol. $45 v_{1}$. Para los actos de corso y piratería en el Mediterráneo con respecto tan solo a la Corona de Aragón y su repercusión negativa en el comercio medieval, véase, por ejemplo, Nuria Colla Y JULIÁ, «Aspectos negativos del tráfico marítimo en el siglo XV: Actos de piratería y consecuencias para el comercio internacional. Corsarios en las costas de la Corona de Aragón", en Instituciones económicas, sociales y politicas de la época fernandina (Zaragoza 1962) págs. 113-139; y Francesco GiUnTA, Aragoneses y catalanes en el Mediterráneo (Barcelona 1989) págs. 89-91.

${ }^{51}$ BREIDENBACH fol. 45va (como mínimo ejemplo); y Giusseppe BELLINI, «Los turcos en las crónicas españolas de viajes de los siglos XV y XVI», Quaderni di Letterature Iberiche e Iberoamericane 3 (1985) págs. 5-26.

52 El tema de las tempestades en escritos de viajes es algo reiterado; de hecho, ya el apóstol Pablo lo recoge (Hechos de los Apóstoles 27, 18-20). Una de las posibles consecuencias de tal eventualidad eran los naufragios, que llegaron a constituir desde la perspectiva literaria un importante motivo de creación: Homero, en el mundo griego (Odisea [ $1^{\mathrm{a}}$ reimpr. Madrid 1986] canto V vv. 291-393 págs. 178181); Virgilio, en el orbe latino (Eneida [Madrid 1992] lib. I vv. 91-141 págs. 142143); Gonzalo de Berceo, en la literatura hispánica medieval (Milagros de Nuestra Señora [Madrid 1989] milagro XXII págs. 169-175), etc. En pleno Renacimiento ibérico el tema alcanzó un mayor desarrollo: la obra de Alvar NúÑEZ CABEZA DE VACA, Naufragios (ed. Trinidad BARRERA [Madrid 1985]), o el estudio de Giulia LANCIANI, «Una historia trágico-marítima», en Lisboa extramuros, 1415-1580, dir. Michel Chandeigne (Madrid 1992) págs. 89-117, dan buena fe de ello.

${ }^{53}$ BREIDENBACH fol. $161 \mathrm{r}_{1}$.

${ }^{54}$ La primera edición de la obra de nuestro religioso alemán (Maguncia 1486) tiene unos capítulos, omitidos en la impresión española, que reflejan algunos de los referidos inconvenientes de la navegación: remedios para el mareo (20) y precauciones contra moscas, piojos, pulgas y sabandijas (21) (DAVIEs Breydenbach pág. XI). Una de las causas que podía diezmar una tripulación era la peste 
Por todo eso, no resulta extraño que el miedo a la muerte estuviera presente en ocasiones entre los temores de los viajeros. Si alguien se moría, o se echaba el cuerpo al mar ${ }^{55}$ o se lo trasladaba a un lugar terrestre definitivo ${ }^{56}$; lo primero resulta curioso teniendo en cuenta la superstición marinera de que las aguas no lo consentían:

Quando esto vimos parecia fengida la grande mentira delos marineros 'que muchos cuerpos de peregrinos y nobles varones lançan en las ondas 'dando a entender que no las çufre despues de muertos el mar ${ }^{57}$.

En el momento en que el peregrino pisaba Tierra Santa, bien podía creer que bajo la tutela de los religiosos franciscanos (y sus consejos) desaparecían definitivamente las dificultades que le impedían el logro de su sueño (Apéndice I) ${ }^{58}$ :

y pienso que ninguno delos peregrinos pudiesse passar alla seguro: si estos frayles ende no fuessen. porque los moros 'y en mayor grado los otros hereges delas otras naciones tienen de nosotros mucho enojo 'y nos abhorrecen'y mal nos quieren ${ }^{59}$;

(BREIDENBACH fols. $54 r_{1}$ y $158 r_{1}$, por ejemplo). Otro factor que influía en el desarrollo de la vida en el barco era la alimentación; su carencia o mala calidad repercutía en la salud de los tripulantes (BREIDENBACH fols. $41 \mathrm{v}_{1}$ y $157 \mathrm{r}_{2}$ da unos mínimos ejemplos sobre la dieta, basada en «carne fresca», «estruciones», «pan», «vino» y «viscocho»). Véase Fernando LóPEZ-Ríos FERNÁNDEZ, Medicina naval española en la época de los descubrimientos (Barcelona 1993).

${ }_{55}$ BREIDENBACH fol. $157 \mathrm{v}_{2}$. Un ejemplo del siglo XII lo hallamos en Ibn YuBAYR, A través del Oriente: El siglo XII ante los ojos, ed. Felipe Maíllo SalGADO (Barcelona 1988) pág. 366.

${ }^{56}$ Ambas soluciones llegaron a estar legisladas; véase José DANón y Beatriz DANÓN-CAMPÓN, «Notas sobre la medicina naval en el Mediterráneo occidental durante los siglos XIV y XV», en $X X X$ Congreso Internacional de Historia de la Medicina (Düsseldorf 1988) pág. 49.

${ }^{57}$ BREIDENBACH fol. $158 \mathrm{r}_{\text {. }}$. En el orbe hispano-cristiano medieval el tema aparece, por ejemplo, en Gonzalo de BERCEO (Milagros, milagro XII e. 598 pág. 171) y en el Libro de Apolonio (ed. Dolores CoRBElla [Madrid 1992] ee. 273-283 págs. 166-169).

${ }^{58}$ Recogidos en BREIDENBACH fols. $57 \mathrm{v}_{2}-58 \mathrm{r}_{1}$ y señalados por Félix Fabri (PETERS Jerusalem págs. 427-430).

${ }^{59}$ BREIDENBACH fol. $131 \mathrm{r}_{2}$. Era encomiable la labor de ayuda espiritual y material, así como de guía, por parte de los religiosos de Asís en favor de los palmeros. El ejemplo más explícito de ello aparece en BREIDENBACH fol. $131 \mathbf{r}_{1}-\mathrm{r}_{2}$. El custodio franciscano que conoció el deán se llamaba Paulus Arrivabene de Canneto (en torno a su figura véase ARCE «Dos custodios» pág. 419). La consideración hacia los guías ya aparece en el primer texto peregrino hispano que se conoce (EgERIA págs. 180-181; vid. también MARAVAL Lieux Saints pág. 166). 
pero en verdad no era así: los variados caminos obligaban al uso de diferentes medios, tanto para realizar el viaje como para sortear desagradables acontecimientos ${ }^{60}$.

Por la lectura de la obra de Bernardo de Breidenbach comprobamos distintos modos de traslado. En Palestina normalmente se hacía el camino en asno ${ }^{61}$; cuando en ciertas ciudades estos animales de carga no estaban permitidos, entonces se hacía el camino a pie ${ }^{62}$. En desplazamientos a «Alcayre» y luego hasta Alejandría se utilizaba sobre todo el camello ${ }^{63}$; en las ciudades egipcias, asnos ${ }^{64}$, y pequeñas embarcaciones para alcanzar Alejandría ${ }^{65}$.

Con tantas idas y venidas, tantas vueltas y revueltas, y por más que Tierra Santa viviese bajo el control mameluco:

tengo yo por cierto que si moros puros touiessen las tierras sanctas en manos: no se daria consentimiento que algun cristiano a ellas entrasse 'por ser tan terrible la enemiga: empero como el mismo Soldan es de aquellos 'y los que tiene en las armadas 'ahun fallamos defension alguna ${ }^{66}$;

era muy frecuente que surgieran problemas. $Y$ así, al igual que cuando hablábamos de los peligros en el mar, también en tierra el peregrino se encontraba con dos tipos de experiencias nada gratas, unas producto de la mano del hombre y otras por causas naturales.

\footnotetext{
${ }^{60}$ Para una atención general a los avatares de los palmeros durante sus trayectos por tierra acúdase a PETERs Jerusalem págs. 427-478. Puede verse un ejemplo hispano en el siglo XV en José Antonio OCHOA ANADÓN, «El viaje de Pero Tafur por Tierra Santa», en Actas II Congreso Internacional de la Asociación Hispánica de Literatura Medieval (Alcalá de Henares 1992) vol. II págs. 597-608; y José A. OCHOA, «La Descripción de Jerusalén en Pero Tafur», en Literatura Medieval: Actas do IV Congresso da Associaçao Hispânica de Literatura Medieval (Lisboa 1993) vol. III págs. 147-156.

${ }^{61}$ BREIDENBACH fols. $41 \mathrm{v}_{2}$ y $57 \mathrm{r}_{2}$ : los pasajes se refieren a la contratación previa de asnos hecha en Venecia con el patrón de la galera y a su utilización desde Jaffa. La razón para usar este medio de transporte nos la explica José Antonio OCHOA ANADÓN: «[...] en 1167 se prohibió a los cristianos montar caballos o mulas en Egipto, ley que no fue derogada por la dinastía mameluca, que la trasladó a tierras palestinas» («El viaje» págs. 598-599).

${ }^{62}$ BREIDENBACH fol. $58 \mathrm{v}_{2}$, es el ejemplo más significativo.

${ }^{63}$ BREIDENBACH fols. $143 \mathrm{r}_{2}$ y $148 \mathrm{v}_{1}$, en el recorrido hasta las puertas de El Cairo; y $154 \mathrm{v}_{2}$, sobre el corto trayecto hasta la ciudad del delta.

${ }^{64}$ BREIDENBACH fol. $151 \mathrm{v}_{1}$.

${ }^{65}$ BREIDENBACH fols. $154 \mathrm{r}_{1}-\mathrm{v}_{2}$.

${ }^{66}$ BREIDENBACH fol. $151 \mathrm{r}_{1}-\mathrm{r}_{2}$.
} 
Con respecto a las primeras, nuestro texto no olvida mencionar toda clase de abusos, bofetadas, heridas, insultos ${ }^{67}$, e incluso la muerte, tal y como le sucedió a uno de los compañeros del deán ${ }^{68}$. Estas situaciones podían provocar actos de venganza por parte de los propios peregrinos cuando volvían a las galeras dispuestas para el regreso ${ }^{69}$. No es raro, por ejemplo, que viajaran armados en el camino hacia El Cairo ${ }^{70}$. La situación podía hacerse hasta tal punto desagradable que el propio autor renuncia en ocasiones a describirla guiado por buenos fines ${ }^{71}$ : no desanimar al lector en hacer una peregrinación.

Las dificultades de índole natural tampoco fueron obstáculos para los viajeros: ni las enfermedades ${ }^{72}$, ni las inclemencias del clima o del desierto impedían alcanzar el gozo de andar por lugares bíblicos.

\subsection{El dinero}

Si para trayectos tan largos convenía tener fortaleza de espíritu, el alto coste del viaje sobre todo en los siglos XIV y XV obligaba también a contar con un considerable apoyo económico ${ }^{73}$ :

[...] donde fallamos muchos generosos condes y varones y caualleros 'y otras muchas personas de cuenta 'dela yglesia como del mundo los quales vinieron enel lugar mismo de partes diuersas dela christiandad: assi con tal zelo santo mouidos para visitar los santos lugares ${ }^{74}$

${ }^{67}$ BREIDENBACH fol. $154 r_{1}$.

${ }^{68}$ BREIDENBACH fol. $57 v_{1}$.

${ }^{69}$ Acerca también de las consecuencias que semejantes comportamientos tenían sobre los palmeros que todavía deseaban permanecer un tiempo vid. BREIDENBACH fol. $142 r_{2}$.

${ }^{70}$ BREIDENBACH fols. $147 \mathrm{v}_{2}-148 \mathrm{r}_{1}$.

71 De ello podemos encontrar una pincelada en BREIDENBACH fol. $142 \mathrm{v}_{1}$.

${ }^{72}$ El conde de Solms, muerto de disentería, es una clara muestra de ello (BREIDENBACH fol. $156 \mathrm{r}_{1}$ ).

${ }^{73}$ Sobre este punto y la peregrinación de Bernardo de Breidenbach, véase UHLHORN «Breidenbachschen Pilgerfahrt» págs. 110-111.

${ }^{74}$ BREIDENBACH fol. $41 r_{1}$, y JACOBY «Pèlerinage médiéval» págs. 35-36. Si atendemos al siguiente comentario, la situación apenas había cambiado en pleno siglo XVI: «Que el camino de Hierusalem ningún pobre le puede ir, porque al menos gasta quarenta escudos y más, y por allá maldita la cosa les aprobecha pedir ni importunar» (Viaje de Turquía, ed. Fernando G. SAlinero [3 $3^{a}$ ed. Madrid 1986] 
Para quien quisiera comerciar o viajar se hacía conveniente el recurso del cambio y del crédito en un mundo en que se usaban muy variadas monedas ${ }^{75}$. Y para mostrar lo dicho sólo hay que examinar la diversidad que conoció el religioso de Maguncia en su desplazamiento, según un Manual mallorquín de mercadería fechable entre 1481 y 1491:

Candia y Xipre.- En Candia y Xipre és la moneda qui y core d'or: ducats e moltes altres monedes d'or. Lo ducat val 6 lliures. A y moltes altres monedes dolentes que bilonegen segons lo ducat, e tots temps lo ducat val més de les altres monedes d'or 5 sous més y 5 sous menys.

Rodes.- En Rodes cora tota manera de moneda d'or. A y moneda qui ha nom joanet e aspres, los pixols; e 32 pixols fan 1 juanet; e 2 aspres fan 1 joanet; e 16 pixols fan aspre. Lo ducat venecià val 60 aspres; ducat de Monseyor lo Mestre, 58 aspres. A y moltes altres monedes, les quals bilonegen segons que val lo ducat. E més y a florins, que val 1 florí 20 aspres.

Alexandria, Al-Caire e Domàs qui és del soldà.- En Alexandria. Al-Caire e Domàs, coren ducats cera fins, qui són ducats de la terra; e volen y molt los ducats valencians (sic por venecians). De moneda blanqua, hi ha moneda que allà anomene darms, maydins e quirats: e 16 darams fan 1 maydi, e 20 maidis fan 1 quirat, e 26 quirats fan 1 ducat. Valen hi altres monedes les quals billonegen segons que val lo ducat [...].

Piça, Florença e Venèssia.- En Piça, Florença e Venècia coren tota menera de ducats e lo ducat val 6 lliures. A y de moltes altres monedes, que són molt delectes, qui les bilonegen segons que val lo ducat. Es ver y coren molta moneda d'or però ducat val tots temps 5 sous més e 5 sous menys [...].

Alemània.- En Alemània coren florins d'or, i val lo florí (en blanco) ${ }^{76}$.

En una peregrinación como la del germano Bernardo de Breidenbach los gastos eran considerables, no sólo para atender las

pág. 119). Por ejemplo, el pasaje costaba 40 ducados en 1457-1462, 20 en 1470, 55 en 1480, 42 ducados cuando peregrina Bernardo de Breidenbach y 40 ducados en 1490 (DAVIES Breydenbach pág. XII).

${ }^{75}$ Para comprender la importancia de semejantes métodos mercantiles en aquella época basta con recurrir a Pero Tafur (Francisco LóPEz ESTRADA, «Pedro Tafur, trotamundos medieval (I)», Historia 1698 [1984] págs. 114-116).

${ }^{76}$ Francisco SEVILlano COLOM, «Monedas que circulaban en el Mediterráneo a fines del siglo XV», en I Congreso Internacional págs. 728-730. 
propias necesidades, sino también debido a razones creadas por individuos no pertenecientes al grupo palmero pero a él vinculados. Ya incluso antes de emprender la marcha había que hacer unos preparativos que costaban una significativa cantidad de recursos. El propio conde de Solms llegó a contratar, no obstante, los servicios de un sastre adicional como una de las primeras medidas a la hora de preparar el viaje ${ }^{77}$.

Tales desembolsos no quedaban ahí, ya que enseguida el viajero tenía que afrontar el tema del transporte. Así, por ejemplo, en Venecia, aparte de hacer acopio de provisiones, convenía hacer un contrato con el patrón de la galera, lo que suponía un ineludible pago: la mitad, en la ciudad véneta; la otra, en Jaffa (Apéndice II) ${ }^{78}$. Lo curioso de semejantes acuerdos es que no se limitaban al viaje en la nave, sino que incluían otras cuestiones: cabalgaduras, intérpretes, peajes, salvoconductos en Tierra Santa, etc. Otros pagos se hacían en Palestina dependiendo del arbitrio de cada viajero: provisiones ${ }^{79}$, limosnas para los franciscanos ${ }^{80} \mathrm{y}$ visitas a monumentos ${ }^{81}$ son ejemplos típicos ${ }^{82}$.

Si luego los palmeros querían desplazarse con seguridad al monasterio de Santa Catalina y a continuación llegar a El Cairo, era necesario contraer un nuevo compromiso, ahora con las autoridades de Jerusalem. Y otra vez había que pagar: la mitad, en la ciudad santa; la otra, en Gazera ${ }^{83}$. Una vez llegados a la capital mameluca, de nuevo urgía aparejar la estancia. Entonces ya no se contaba con el asesoramiento y ayuda de los franciscanos; allí convenía el apoyo del calino mayor, quien a cambio de buenas monedas que se pagaban al final de la estancia proporcionaba casa,

\footnotetext{
77 UhLHORN «Breidenbachschen Pilgerfahrt» pág. 108.

${ }^{78}$ BREIDENBACH fols. $41 r_{2}-42 r_{1}$. Este aspecto del viaje suele mencionarse en los textos de los peregrinos, como vemos en el de Ulrich Brunner, que estuvo en Tierra Santa en 1470 (Annie FAUGÈRE, «L'Autre et l'Ailleurs dans quelques récits de voyage allemands», en Les récits págs. 27-28); en relación con acuerdos entre peregrinos españoles y patrones venecianos, véase TAFUR Andanças pág. 41 (siglo XV) y LISBOA Viaje a Oriente págs. 53-55 (siglo XVI).

${ }^{79}$ BREIDENBACH fol. $57 \mathrm{r}_{1}$.

${ }^{80}$ BREIDENBACH fol. $61 \mathrm{r}_{2}$.

${ }^{81}$ BREIDENBACH fol. $61 \mathrm{v}_{2}$.

${ }^{82}$ La oferta de objetos para comprar que se presentaba a los peregrinos en Tierra Santa, especialmente a la entrada del Santo Sepulcro, era tan apabullante que mereció la crítica de Félix Fabri (PETERS Jerusalem pág. 443).

${ }^{83}$ BREIDENBACH fols. $72 \mathrm{v}_{2}$ y $141 \mathrm{v}_{2}-142 \mathrm{r}_{2}$.
} 
guías y transporte, incluida la ayuda para la marcha al puerto de Alejandría ${ }^{84}$. También para este trayecto había que gastar dinero en comida ${ }^{85}$, dádivas ${ }^{86}$ y socorro ${ }^{87}$, visitas a lugares de interés ${ }^{88} \mathrm{e}$ incluso a ciudades, como la citada Alejandría ${ }^{89}$.

No obstante esta aparente quietud, la realidad en ocasiones ensombrecía los ánimos de los peregrinos, sobre todo en lo referente a los abusos ${ }^{90}$ y a los robos ${ }^{91}$ por las gentes del país; por su parte, los patrones de galeras también se aprovechaban de los viajeros, sabedores de la necesidad que se tenía de tratar con ellos ${ }^{92}$. Por todo eso, si a los gastos más o menos calculados se añadían los imprevistos, los desembolsos resultaban muy altos. Estos aumentaban cuando el peregrino deseaba comprar supuestos recuerdos, ya profanos ${ }^{93}$ ya religiosos ${ }^{94}$.

\subsection{Las lenguas de Tierra Santa}

Tengo para mí que el desconocimiento de idiomas es quizás el mayor obstáculo para provechosos viajes. En la época en que nos movemos la cuestión podía solucionarse en Europa, en líneas generales, con el latín. Y es que tal importancia llegó a cobrar durante el Medievo la lengua de Roma, que incluso el mongol Abaga en el siglo XIII la utilizó preferentemente en sus misivas con el papa. Resulta lógico así que en 1267 Clemente IV se sorprendiera

\footnotetext{
${ }^{84}$ BREIDENBACH fol. $154 \mathrm{r}_{1}$.

${ }^{85}$ BREIDENBACH fol. $147 \mathrm{r}_{2}$.

${ }^{86}$ BREIDENBACH fol. $146 \mathrm{v}_{2}$.

${ }^{87}$ BREIDENBACH fol. $151 \mathrm{r}_{2}$.

${ }^{88}$ BREIDENBACH fol. $149 \mathrm{r}_{2}$.

${ }^{89}$ BREIDENBACH fols. $155 r_{1}, 155 r_{1}-r_{2}$ y $157 r_{1}$. En dos de las puertas de esta ciudad y en su ribera se pagaba obligatoriamente el diezmo; de ello quedaban exentos los religiosos. En relación con los judíos Mešul-lam da Volterra nos dice lo siguiente: «Cuando llegamos a la puerta nos registraron y nos encontraron nuestro dinero, a pesar de que estaba (oculto) bajo mis pies, y me tomaron en cuenta (a razón del) 10 por ciento, y después me devolvieron el 9 por ciento, pues los judíos no pagan más que el 1 por ciento, aunque te descubran que no se lo has declarado» (MAGDALENA NOM DE DÉU Relatos de viajes pág. 48).

90 BREIDENBACH fol. $154 \mathrm{v}_{1}$.

${ }^{91}$ BREIDENBACH fol. $154 \mathrm{v}_{1}$.

${ }^{92}$ BREIDENBACH fols. $156 \mathrm{v}_{2}$ y $161 \mathrm{v}_{2}$.

${ }^{93}$ BREIDENBACH fol. $154 \mathrm{r}_{2}$.

${ }^{94}$ PeTERs Jerusalem pág. 448.
} 
al recibir una en lengua mongola; todo se aclaró cuando en 1268 el soberano oriental contestaba, en latín según la costumbre, lamentando el hecho y justificándose por la ausencia de su escriba latino ${ }^{95}$.

La solución del latín quedaba en gran medida descartada en los países musulmanes y en concreto en Tierra Santa. Por eso es comprensible que el palmero viera con buenos ojos la presencia de entendidos en lenguas entre los compañeros de viaje ${ }^{96}$, de intérpretes desde la misma llegada a los Santos Lugares ${ }^{97} \mathrm{o}$ de franciscanos custodios de los sagrados sitios, los cuales podían entenderse con los peregrinos en sus idiomas nacionales ${ }^{98}$. Este aspecto recuerda la labor de los religiosos en la Palestina del siglo IV, cuando traducían la liturgia en griego al siriaco para el pueblo y al latín para los «latinos» presentes ${ }^{99}$.

La importancia de esas personas se acentuaba por el hecho de cohabitar en Palestina un cúmulo de pueblos: «abbasinos», armenios, georgianos, griegos, «jacobitas», judíos (Apéndice III), maronitas, nestorianos, sarracenos y «surianos», y por ende, de lenguas:

Estos abbasinos siquier indianos: ahun que en jerusale $m$ y tierra sancta saben y entiendan la moriega lengua: y della quando les plaze vsan: no menos tienen su propio lenguaje y alphabeto: el qual tiene .xlvij. letras: segun en las siguientes figuras son escriptas $[\ldots]$.

$\mathrm{Su}$ alphabeto y propria letra es la siguiente deyuso escripta.

Alphabeto delos armenios [...].

Tienen ellos [los georgianos] la griega letra y lengua en sus officios y escripturas: en los negocios otros vsan la caldea 'o moriega: cuyos alphabetos ya fueron arriba señalados [...].

En los officios diuinos [los griegos] vsan la lengua griega 'que todos los legos entender la pueden: en todos los otros negocios que en jerusalem y tierra sancta hazen: hablan en arabigo 'como los moros. Su propio alphabeto y letra todo al natural es lo siguiente [...].

${ }^{95}$ J. GIL, En demanda del Gran Kan: Viajes a Mongolia en el siglo XIII (Madrid 1993) pág. 134.

${ }^{96}$ BREIDENBACH fol. $142 \mathrm{v}_{1}$.

${ }^{97}$ Esta cuestión incluso se concertaba con el patrón de la galera (BREIDENBACH fol. $41 \mathrm{v}_{2}$ ).

${ }^{98}$ BREIDENBACH fol. $57 \mathrm{v}_{2}$.

${ }^{99}$ Egeria págs. 316-319. 
Tienen [los jacobitas] diuersas formas de letras: segun el costumbre 'o diuersidad en las prouincias donde habitan: empero su letra y alphabeto general a todos es el presente [...].

Hablan ellos [los judios] en aquellas tierras la arabica lengua: y entre si mismos vsan sus propias lengua y letras hebraycas: segun enel siguiente alphabeto stan escriptas [...].

No tienen [los maronitas] propia letra que scriuan 'sino la chaldea 'o la moriega 'delas quales vsan [...].

En sus escripturas y enlos officios diuinos [los nestorianos] vsan lengua y letra chaldea. en jherusalem y tierra sancta hablan la lengua de algarauia para sus negocios. en las otras tierras y reynos que biuen 'vsan de aquellas lenguas que tienen [...].

@ Los sarracenos siquier moros vsan la lengua arabica con su letra: la qual contiene .xxxj. letras: segun en el siguiente alphabeto estan figuradas [...].

En los negocios mundanos [los surianos] hablan lengua morisca: en los diuinos y espirituales vsan la griega. Algunos en ellos vsan el chaldeo 'quando les plaze: porque bien lo saben. Y la verdadera letra y alphabeto dela scriptura y lengua chaldea es la siguiente $[\ldots]^{100}$.

Asunto diferente era cuando, ora en alemán, ora en italiano, los habitantes del país recriminaban a los palmeros ${ }^{101}$, o cuando pequeños comerciantes que les acosaban intentaban hacerse entender por medio de una mezcolanza de lenguas romances. Juan del Encina escribió un Villancico contrahaziendo a los mócaros que sienpre van ynportunando a los peregrinos con demandas que da alguna idea de lo que el deán oiría de tales mercaderes:
Benda ti istrán plegrín,
Benda -tú peregrino extranjero-
benda, marqueta, maidín.
benda, «marchetto», maidín.

Benda, benda stringa da, da agugeta colorada

Por una benda, una benda yo doy agujeta colorada;

${ }^{100}$ BREIDENBACH fols. $126 \mathrm{v}_{2}, 125 \mathrm{r}_{2}-\mathrm{r}, 125 \mathrm{v}_{2}, 122 \mathrm{v}_{2}, 124 \mathrm{r}_{2}, 121 \mathrm{r}_{2}, 127 \mathrm{r}_{1}, 124 \mathrm{v}_{1}, 120 \mathrm{r}$ y $123 \mathrm{r}_{2}-\mathrm{v}_{2}$. Véase Miguel Ángel de BUNES IBARRA, La imagen de los musulmanes y del norte de Africa en la España de los siglos XVI y XVII: Los caracteres de una hostilidad (Madrid 1989) págs. 92-96.

${ }^{101}$ Esto junto al uso de determinados idiomas europeos por parte de los franciscanos nos da idea de la nacionalidad de los visitantes más habituales (PETERS Jerusalem pág. 430). 
dali moro namorada y Alá ti da bon matín.

Por Alá te rrecomenda dar maidín, marqueta, benda,

con bestio tuto lespenda: xomaro estar bon rroçín.

Peregrín taybo cristián, si querer andar Jordán pilla per tis jornis pan, que no trobar pan ne vin.

Pilla, pilla per camino palastro, bona galino, bono fica, taybo fino y taybo zucarrazín.

Pilla lobo coto ades, per benda dar dos e tres, per marqueta çinca seys, dez e duz per un maydín.

Per marqueta e maydín dar ovos, haba per manjar, marqueta bayoco estar, dos bayocos un maydín.

\section{Fin}

Marçela çinco maidines valer Judea confines, taybos, no marfuzes rruynes, sy xonar bono tintín. dásela a tu enamorada mora y Alá te da buena mañana.

Por Alá te recomiendo gastar un maidín, un «marchetto», [ una benda por una bestia completa: un burro es buena cabalgadura ${ }^{102}$.

Buen peregrino cristiano, si deseas ir al Jordán lleva pan para tu viaje, porque no encontrarás ni pan ni vino.

Lleva, lleva para el camino un pollo, una buena gallina, buenos higos, buen vino y buenas uvas dulces.

Lleva huevos cocidos ahora, por una benda yo doy dos o tres, [por un "marchetto" cinco, seis, diez o doce por un maidín].

Por un "marchetto" y maidín doy huevos y habas para comer; un "marchetto" vale un bayoco, dos bayocos un maidín.

\section{Fin}

Un marchetto vale cinco maidines en territorio de Judea, buenos, no malos ruines, que tengan buen sonido ${ }^{103}$.

En Tierra Santa también era posible escuchar lenguas peninsulares y no sólo de parte de los peregrinos. Por un lado, y en el

${ }^{102}$ Corregimos en la palabra una molesta errata de imprenta en la edición usada.

$103 \mathrm{~J}$. del ENCINA, Obras completas (Madrid 1986) vol. II págs. 268-270. Ana M. RAMBALDO translada al español la versión inglesa de esta poesía; nosotros sólo la hemos reproducido. 
ámbito cristiano, aparecen las figuras de Antonio Cruzado y Mauro de San Bernardino, custodios generales franciscanos durante los años 1484-1487 ${ }^{104}$ y 1501-1504 ${ }^{105}$, respectivamente, y por tanto responsables eclesiásticos de los religiosos encargados de la atención y del cuidado de los sacros lugares. Y por el lado musulmán, sobresale Taghribirdi, servidor muy cercano del sultán de Babilonia como intérprete y presentador de embajadores (1502) y como legado y mensajero (1506-1507) ${ }^{106}$. Así pues todavía seguía vigente el interés hispano por la zona, mantenido en la Península Ibérica durante siglos.

\section{APÉNDICE I}

[Cinco reglas muy principales de los franciscanos de Tierra Santa]

@ A .ix. de julio 'por mandamiento del guardiano 'vn frayle suyo celebro la missa: y quando llego al offrecer 'boluio a nosotros 'y nos jnformo de todo el orden que nos cumplia tener en la casa y tierra sancta: y nos hablo en lengua latina 'ytaliaca 'y alemana en las quales dio cinco avisos ${ }^{107} \mathrm{y}$ reglas sabidas en esta forma. Mucho amados en cristo jesu 'es necessario seays sabidores de cinco reglas muy principales: por que no sean puestos en vano los grandes trabajos y muchas despensas que fasta llegar aca çuffristes peregrinando en tierras estrañas muy apartadas de vuestras naciones 'y tan peligrosas.

@ Es la primera 'que si alguno de vos incurrio en la sentencia de excomunion 'por hauer venido sin consentimiento del sancto padre 'sepa que tenemos su auctoridad 'y mayormente el padre guardiano 'para que podamos dar absolution a qualquier cristiano 'que viene en este sancto camino: con solo dezir vn pater noster 'con piensa deuota y voluntad sana y libre 'con aquella misma le sera luego por nos otorgada: [fol. LVIIIr ${ }_{1}$ ] porende haued gozo entero: y porque ganastes de dios tanta gracia que os ha fecho mereçedores de ser allegados en estas pisadas santas que traeys: y os dexo

\footnotetext{
${ }^{104}$ ARCE «Dos custodios» págs. 417-432.

105 P. García BARriuso, España en la historia de Tierra Santa (Madrid 1992) pág. 121.

106 BREIDENBACH fols. $148 \mathrm{v}_{1}-154 \mathrm{r}_{1}$; RodRíGuez MoÑino «Viaje a Oriente» pág. 120; MÁRTIR DE ANGLERÍA Una embajada págs. 93 y 95; Antonio de la TORRE, Documentos sobre relaciones internacionales de los Reyes Católicos (Barcelona 1966) vol. VI pág. 269; Salvador GARCíA, «Tres españoles en la corte del último sultán de Egipto (1501-1517)», Boletín de la Asociación Española de Orientalistas 7 (1971) págs. 122-123 y 126-129; y GARCía BARriuso Tierra Santa págs. 121-125.

107 Inc.: avises.
} 
assi visitar las muy sagradas tierras en que stays: donde le plugo al redenptor obrar la salud nuestra entera.

@ La segunda regla que tenga qualquiera delos peregrinos: muy indubitada fe verdadera de buen cristiano en su coraçon: que de otra suerte seria venido del todo en vano.

@ La regla tercera 'es que la consciencia tenga muy limpia: y con verdadera y gran contricion se arrepienta de sus pecados: con voluntad y buen propuesto de se guardar para delante.

@ La quarta regla es 'que qualquiera con todas sus fuerças haya devocion de bien visitar estas andadas y romeage delos muy sagrados lugares y casas por que venistes.

@ La quinta regla es 'que se guarde qualquier de vosotros con muy gran estudio 'que jamas ande 'ni pise encima delas sepulturas delos paganos por que lo tienen a muy gran injuria y han por ello enojo muy grande. Y quando viessen andar alguno por encima ellas hauria peligro de cruel muerte.

\section{APÉNDICE II}

La forma y pacto que hizo el capitan dela galera con los caualleros y peregrinos arriba nombrados

@ El primer pacto fue 'que el patron de la galera 'deue leuar los peregrinos al puerto de joppen ala tierra santa'y dende boluer con ellos mismos fasta venecia donde partieron. y esto se deue bien assegurar segun el tiempo y forma çufrieren

@ Fue condicion que los peregrinos luego scogiessen dos hombres dellos 'que al principio enel mismo puerto 'y despues en todos donde arribassen: touiessen cargo de reconocer'si el patron es bien proueido de seruidores 'para seruicio de los nauios: segun necessidad esto quisiere. por que si alguno dellos morria 'fuesse otro puesto en lugar suyo /a todas despensas del mismo patron.

@ Deue tener armas el dicho señor dela galera 'con que se puedan armar .lxxx delos nauegantes 'para defension de los enemigos si los fallaren.

@ Fue obligado el mismo patron de ir y llegar en los lugares 'o puertos: que suelen arribar las fustas: segun el costumbre de los antigos: donde no pueda star por mas tiempo de dos 'o tres dias si las tempestades 'o la fortuna del mar que suele: no lo empachassen: y si algunos delos peregrinos quisieren llegar a [fol. XLIv ${ }_{1}$ ] ver a Nicosia ciudad de chipre'sea tenido de los esperar enel puerto dela jnsula misma. Y quando boluieren dela tierra sancta pueda el patron tardar por iij. dias en cadavn puerto'no mas adelante: y esto por causa de mercadurias: empero por esso queden los lugares ya señalados alos peregrinos enel nauio seguros 'libres 
'y desenbargados en tal manera que por ninguna mercaduria siquier jnteresses tomar no se puedan.

@ Fue condicion que deuen hauer los peregrinos el comer dos vezes en cadavn dia: segun que personas de honrra mereçen. y si por alguna causa no pudiere qualquier peregrino comer ala mesa del dicho patron: que le sea dado comer a su parte segun es costumbre a tales hombres Y ahun sea mas obligado: que de venecia fasta que llegue ala tierra santa /y dende buelua enel lugar mismo donde partieron: sea tenido de dar pan y vino y carne fresca 'todo muy bueno: con las prouisiones que son razonables.

@ Quando quisieren los peregrinos salir en tierra por agua dulce 'o por algunas necessidades que venir suelen 'sea tenido el dicho patron de dar vna barca donde sallir puedan'y compañeros para que los lieuan y despues bueluan a su nauio.

@ Deue defender el dicho patron: assi en tierra como enel mar 'que los peregrinos no sean tratados en mala forma de otros algunos 'ni en los fechos ni con palabras. y esto faga quanto su poder le abastare.

@ Passo en esta presente concordia 'que diesse tiempo el dicho patron 'para que pudiessen los peregrinos bien visitar la tierra santa: y los ${ }^{108}$ esperasse con la galera. y ahun que vaya el en persona en la visita con ellos mismos fasta el rio jordan: y [fol. XLIv ${ }_{2}$ ] los guarde como se acostumbra de los infieles. lo qual guardado bueluan en vno todos al puerto.

@ Si acaeciere morir alguno delos peregrinos: el patron en forma ninguna pueda tomar sus bienes: ni conocer algo de aquellos: antes los dexe 'como el finado los ordinare 'sin contradicion. Si ante moriere que arribassen ala tierra santa 'sea touido boluer el patron la meatad delos dineros que se le deuian dar de su nolit: para que ordenen sus herederos

@ Despues que fueren ya enla tierra y santo sepulcro: si alguno destos dichos peregrinos querran visitar el monte synay donde esta el cuerpo dela señora sancta katelina 'sea el patron luego touido de dar .x. ducados a qualquier dellos 'delos dineros que le hauran dado. lo mismo fagan los peregrinos al dicho patron: si mucha tardança fazer quisieren en jherusalem por que a su causa no se detouiesse con la galera dentro enel puerto. y quando quisieren leuar consigo algun interprete si quier heraute de aquellas tierras a donde fueren sea touido de lo mantener el dicho patron como alos mismos: y drecho ninguno del pueda tomar.

@ Despues que fueren los peregrinos ya en el puerto de japha ${ }^{\prime} y$ puestos en la tierra sancta: sean touidos de pagar ellos al dicho heraute a todos cargos suyos y despensas: assi los peages y salua-

${ }^{108}$ Inc.: las. 
guardia como delas otras seguridades. enlo qual no deue contribuyr el dicho patron. La concordia fecha conel heraute es arbitraria 'segun la forma con el compuesta.

@ Fue condicion 'que por hauer el saluo conducto 'y qualesquiere otras exactiones y costas que haya: en hauer los asnos o caualgaduras 'como en otra forma qualquiere 'deuen quedar todas a cu'ra [fol. XLIIr ${ }_{1}$ ] y cargo del dicho patron. por cuyos trabajos dichos y sus despensas dar se obligaron los peregrinos: pagar quarenta y dos ducados por cadavno la meatad luego enel puerto delos venecianos: la otra llegando en la ciudad Joppen.

@ E si quisieren los peregrinos despues de llegados en jherusale $m$ yr a visitar el monte synay 'o qualesquier otros lugares: el patron sea touido entonce de les consejar la forma que tengan con los infieles: y ser en persona siempre con ellos. y quando en tal tiempo ellos dexaren algunas cosas enel nauio por no las poder consigo leuar: aquellas les haya de tener seguras a todo su cargo: fasta que lleguen dentro en venecia

@ Fue obligado el dicho patron dar en la fusta vn lugar vazio 'donde poner puedan los peregrinos sus prouisiones: y les adreçen sus seruidores algunas viandas 'quando las quieran.

(a) Empero por dar forma deuida en lo conuenido: fuemos obligados al dicho patron'y el a nosotros de llanamente cumplir y tener lo capitulado. y esto fue hecho con juramentos y seguridades firmes y buenas. lo qual si en algo fuesse quebrado por qualquier de todos: a cargo suyo emendado fuesse.

\section{APÉNDICE III}

El siguiente texto forma parte del apartado Sobre las sectas y varios errores de la Tierra Santa. Junto a la visión que tenía Bernardo de Breidenbach acerca del pueblo elegido ${ }^{109}$, el testimonio suscita más curiosidad al presentarse en nuestro incunable zaragozano con dos grabados: uno con la imagen de un judío prestamista ${ }^{110} \mathrm{y}$ otro con el alfabeto hebreo ${ }^{111}$.

${ }^{109}$ El traductor hispano, Martín Martínez de Ampiés, deja sin trasladar una Tabla de intereses.

${ }^{110}$ Tal figura era la imagen tópica, sobre todo en la Europa de la Baja Edad Media. Los reyes propusieron en ocasiones la eliminación de los préstamos, pero los dictámenes no tuvieron éxito, como demuestra, por ejemplo, el Ordenamiento dado por Alfonso XI (siglo XIV). A pesar de lo dicho, la ilustración presente en nuestro incunable queda lejos de las denigrantes que, por ejemplo, podían verse en variados manuscritos medievales (La vida judía en Sefarad, ed. E. Romero [Madrid 1991] págs. 35, 263, 268-289).

${ }^{111}$ En torno al uso de caracteres hebreos en la naciente imprenta europea, véase DAVIES Breydenbach pág. XXVI. 
Para el agudo lector, hemos de decir como dato adicional que el contenido se sitúa muy en la línea de lo escrito por Jacobo de Vitry en su Historia Orientalis (siglo XII), quien de igual modo desarrolló capítulos sobre las diversas gentes que vivían en Tierra Santa ${ }^{112}$. También podemos encontrar el tipo de léxico empleado en la apologética medieval cristiana dirigida contra los judíos. Con ello se advierte la pervivencia y el peso de unos juicios contra una comunidad, los cuales (triste y lamentablemente) no dejarán de aparecer en escritos hispanos del XVI y XVII ${ }^{113}$.

\section{[fol. CXXv] Delos judios que ahun habitan en jerusalem}

[Grabado] [fol. $\mathrm{CXXv}_{1}$ ] EN jerusalem habitan y moran ahun muchos judios por nuestros tiempos 'con sus mujeres y fijos que tienen: son pertinaces y obstinados en su perfidia: teniendo el velo de moyses ante sus ojos: porque no vean la lumbre de vida y verdad: y no quisieron hauer la sciencia de dios eterno 'para que sepan andar sus vias: siendo indignos de alcançar la perdurable bienauenturança 'pues que mataron el remediador de toda natura: como crueles impíos llamando a poncio pilato. la sangre suya sobre nosotros y nuestros fijos. Y como no quisieron la bendicion 'ser les ha quitada: que son odiosos a dios y alos hombres: porque los moros /y las naciones todas del mundo 'a ellos persiguen: y como los yerros de otras ${ }^{114}$ gentes ende se reciten las heregias desta vil gente mi lengua teme querer las contar. Estos judios se interpretan confessores: y a muchos dellos sigue confession 'que ante perfidia los possio. Hebreos se dizen 'o interpretan [fol. $\mathrm{CXXv}_{2}$ ] passantes 'o passaderes: por cuyo nombre son amonestados 'que delos males al bien se recojan'y quieran dexar los yerros primeros Los phariseos y saduceos van por el contrario entre si mesmos. Los phariseos se interpretan diuisos 'o partidos 'siquier apartados: porque de sus costumbres y obseruancias las quales ellos deuterosas llamar han querido. dize[n] que biuen sobre la justicia: assi por ella biuen apartados diuisos del pueblo. Los saduceos se llaman o interpretan justos 'robando el nombre muy enemigo de todas sus obras. la resurrecion delos cuerpos niegan: porque affirman ellos y las almas morir en vn tiempo. tienen solos .v. libros dela ley. las profecias delos profetas no las acojen. Los Esseos dizen ser aquel cristo: que les enseño toda abstinencia. Los morboneos dizen ser christo el que les enseño festiuar los sabba-

\footnotetext{
112 Jacques de VITRY, La traduction de l'Historia Orientalis de Jacques de Vitry, ed. Claude Buridant (Paris 1986) págs. 128-130. La obra del francés fue conocida en la Península Ibérica desde bien pronto, si atendemos a las traducciones que se conservan en la Biblioteca Nacional de Madrid (Ms. 684, siglos XIII-XIV, y Ms. 8173 , siglos XVI-XVII).

113 BUNES IBARRA La imagen págs. 132-137.

114 Inc.: otros.
} 
dos Los Genisteos dize[n] que se llaman: porque del linaje de abraam descienden 'segun se glorian. Quan'do [fol. CXXIr ${ }_{1}$ el pueblo fue catiuado en babilonia muchos dexando sus propias mujeres 'se ayuntaron alas de babilonia y estrañas Algunos otros que delas suyas contentos fueron'o dellas nacidos. despues a la buelta en jerusalem dexaron: y se apartaron de todo el pueblo 'tomando estos nombres de jactancia. Los meristeos fueron llamados 'por que sabian las scripturas 'y no creyendo en los prophetas: porque affirmauan prophetizar por otros espiritus. Meris en griego 'quiere dezir en latin parte. Samaritanos se dizen porque la ley sola guardan ${ }^{115}$ : delos prophetas ninguno creyendo. Estos se dizen Merobabtistas: porque sus vestidos y cuerpos lauan en cadavn dia. Todos estos yerran en muchas partes. Dizen 'o fingen tener dios cuerpo. La trinidad enlas personas diuinas niegan. el christo que speran que ha de venir: dizen que sera hombre puro hecho: y assi lo affirman. creen que jesu nuestro saluador nacio del simiente de joseph y de maria. no piensan que hay algun purgatorio La circuncision que fue dada por el pecado original 'no creen que por ello se haga: mas solo affirman que fue para poner vna differencia 'o distincion por ser ellos conocidos entre los otros. Ahun espe'ran [fol. $\mathrm{CXXIr}_{2}$ ] que su messias tiene de venir: y les dara libertad entera con toda la tierra de promission. El resuscitar de nuestros cuerpos dizen que sera por los deleytes para mil años en este mundo. Delas vsuras o logros alos ajenos no hazen conciencia. Son los mas enellos dados en hazer hechizerias y sortilegios. delos pecados y pensamientos del coraçon 'por abhominables y malos que sean cuydado no tienen. Su ley interpretan segun la letra 'que sola mata: no segun el seso siquier spiritu que viuifica 'o da la vida. En otros muchos yerros condenados y heregias van todos bueltos: segun paresce por la scriptura de su thalmud. la qual de verdad es mas fengida engaño y burla 'que no alguna exposicion ${ }^{116}$. Es vna gente de mala conciencia en todos los tratos de sus ganancias y mercaderias. Cargan de logros tanto sobrados en los christianos 'con tan sobrada enbidia que les tienen que no se falla vn tal estremo en otro linaje ni generacion de todo el mundo 'por enemigos y malos que sean. Hablan ellos en aquellas tierras la arabica lengua: y entre si mismos vsan sus propias lengua y letras hebraycas: segun enel siguiente alphabeto stan escriptas. [fol. CXXIr] [Grabado] ${ }^{117}$.

\footnotetext{
115 Inc.: guarden.

${ }^{116}$ Inc.: exposicióu.

${ }_{117}$ Queremos agradecer a la Dra. Elena Romero la atención que ha prestado a nuestro artículo, haciéndonos muy atinados comentarios y no menos útiles sugerencias.
} 


\section{RESUMEN}

El presente artículo se ocupa de los peregrinajes cristianos a Jerusalem al final del siglo XV: viaje por tierra y mar, dinero y lenguas. Los datos en los que me baso provienen de uno de los más importantes y bellos libros impresos en España: El Viaje de la Tierra Santa de Bernardo de Breidenbach (Zaragoza 1498).

\section{SUMMARY}

The present article attemps to show the Christian pilgrimages to Jerusalem at the end of the fifteenth century: Travel on land and sea, money, and languages. In order to situate this description, the information is obtained from one of the most important and beautiful books printed in Spain: The Viaje de la Tierra Santa by Bernardo de Breidenbach (Zaragoza 1498). 